Cahiers d'études africaines

Durand, Bernard \& Fabre, Martine (dir.). - Le Juge et l'Outre-mer. Tome $1:$ Phinée le devin ou les leçons du passé

Lille, Centre d'histoire judiciaire, 2006, 306 p.

Marie Rodet

\title{
OpenEdition
}

Journals

Édition électronique

URL : http://journals.openedition.org/etudesafricaines/9322

DOI : 10.4000/etudesafricaines.9322

ISSN : $1777-5353$

Éditeur

Éditions de l'EHESS

Édition imprimée

Date de publication : 15 décembre 2007

Pagination : 781-783

ISBN : 978-2-7132-2140-8

ISSN : 0008-0055

Référence électronique

Marie Rodet, « Durand, Bernard \& Fabre, Martine (dir.). - Le Juge et l'Outre-mer. Tome 1 : Phinée le devin ou les leçons du passé », Cahiers d'études africaines [En ligne], 187-188| 2007, mis en ligne le 11 janvier 2008, consulté le 22 septembre 2020. URL : http://journals.openedition.org/etudesafricaines/9322 ; DOI : https://doi.org/10.4000/etudesafricaines.9322

Ce document a été généré automatiquement le 22 septembre 2020

(c) Cahiers d'Études africaines 


\section{Durand, Bernard \& Fabre, Martine (dir.). - Le Juge et l'Outre-mer. Tome 1 : Phinée le devin ou les leçons du passé}

Lille, Centre d'histoire judiciaire, 2006, 306 p.

\section{Marie Rodet}

1 L'équipe de Bernard Durand et Martine Fabre qui a déjà conduit un travail riche sur la justice coloniale sous la Troisième République et la position du juge en situation coloniale (Le juge et l'Outre-mer : les roches bleues de l'Empire colonial, 2004) s'attaque ici au projet ambitieux de placer le juge colonial dans une approche comparative spatiale et temporelle pour la période qui précède l'objet de leurs premières recherches. Ce projet est ambitieux puisqu'il présente quinze travaux s'intéressant aussi bien à la justice à l'époque médiévale, dans les colonies européennes en Méditerranée ou dans le Midi de la France, qu'à la justice consulaire dans les Empires ottoman et chérifien, ou encore à l'organisation de la justice coloniale par les différentes puissances européennes en Afrique, en Inde, aux Antilles, en Amérique latine et en Amérique du Nord. Cet ouvrage tente, tout en tenant compte de l'hétérogénéité des expériences et des stratégies coloniales mises en place au cours des siècles pour s'adapter aux spécificités locales, d'identifier certaines constantes dans la justice coloniale.

Peut-on en effet tirer des expériences précédentes des modèles et des leçons de la justice coloniale? Les articles de cet ouvrage montrent que certains modèles ou méthodes ont pu être utilisés. Le passé juridique et judiciaire, la " mémoire coloniale » ont en effet sans doute toujours joué un rôle inconscient dans les projections et les réflexes d'imitation construits par des siècles d'expérience, d'autant que, Bernard Durand aurait pu l'ajouter, les officiers de justice et les fonctionnaires avaient souvent une formation (parfois succincte) en histoire classique et en droit, en particulier en droit romain, matière considérée comme universelle. Ils avaient donc généralement quelques connaissances quant aux expériences de colonisation de la période antique. 
3 Cet ouvrage confirme tout d'abord le rôle central de l'organisation judiciaire dans les processus de colonisation, de contrôle des populations et de direction de l'évolution sociale (Lesné-Ferret). La présence européenne étant au départ avant tout commerciale, il est impératif d'assurer la sûreté des biens et des personnes et de régler les conflits commerciaux comme le soulignent les trois premières contributions de l'ouvrage. Le droit "voyage " (Vanderlinden) rapidement: dans certaines régions, il s'agira simplement d'obtenir la garantie d'un jugement impartial ; dans d'autres, une concession attribuant un pouvoir de justice ; enfin, certains territoires bénéficieront de traités et de capitulations permettant de développer des juridictions mixtes. Bernard Durand souligne que ces solutions peuvent être parfois des «amorces » de justice de " colonisation ». Les traités comme les capitulations ne sont cependant que rarement à l'origine des choix ultérieurs d'organisation judiciaire coloniale (Vanderlinden).

4 Les nouvelles organisations judiciaires coloniales doivent prendre en compte les autorités et les coutumes locales et la concurrence des autres puissances européennes. C'est l'objet des contributions rassemblées dans le deuxième chapitre de l'ouvrage. Les juges tentent de déterminer le droit applicable et se confrontent du coup à des droits de nature différente : un droit métropolitain « approximatif » adapté aux circonstances locales pour les colons et un droit pour les populations locales dit « autochtone » ou "coutumier" qui est lui-même loin d'être dénué de toute forme d'hybridité et d'invention de la tradition. Dans les premiers temps, on parlera plus volontiers d'usage que de loi ou de règlements (Sankalé). Mais le souci de rationalisation encourage la mise en place d'un système judiciaire formel et unifié, "une synthèse des modèles coloniaux » (Durand) combinant droit métropolitain, droit du pays colonisé et celui hybride issu du phénomène colonial. Dans certains cas, les colonies s'avèrent des laboratoires d'expérimentation de réformes ou de nouvelles structures juridiques qui débouchent sur une "adaptation-expérimation ou inspiration» plus que sur une « imitation-adaptation» (Durand).

5 Ce passage aux institutions coloniales représente souvent une rupture, puisqu'un droit colonial imitant le droit métropolitain est mis en place comme le montrent plus particulièrement, mais pas seulement, les articles du troisième chapitre de ce volume. Ce nouveau droit est étatique, autoritaire et centralisé en remplacement d'un droit local plus consensuel et populaire où l'oralité domine (Bonnan, N'gando). Ces nouvelles institutions continuent à s'appuyer sur une organisation dualiste de la justice entre colons et indigènes, ce processus de formalisation du droit se jouant finalement le plus souvent au détriment de ces derniers (Bonnan, Morin, Lourde). Mais ces nouvelles institutions n'empêchent pas les juges et le personnel judiciaire de continuer à s'appuyer sur des réseaux sociaux complexes nécessaires pour faire fonctionner un système plus formalisé et du coup moins flexible et moins adapté aux réalités locales. Certains parleront de corruption qu'il faut endiguer afin que le droit métropolitain soit formellement appliqué, d'autres de mal nécessaire (Herzog, Durand, Destouches et Gobert). Ces réseaux de pouvoirs parallèles se développent alors que l'administration tente de plus en plus une mise sous tutelle de la justice, ce qui provoque de nombreux conflits entre les deux pouvoirs.

6 Malgré la diversité des situations coloniales, on retrouve donc des institutions judiciaires confrontées à des situations comparables. Du fait du climat, les décès sont nombreux, le personnel judiciaire est difficile à recruter et l'on recourt régulièrement à des intérimaires peu formés, officiels ou officieux, pour suppléer (Durand, Dauchy, 
Sankalé). Les décisions budgétaires et la recherche d'efficacité font que le cadre judiciaire est réduit à sa plus simple expression, le juge a des compétences étendues et est le plus souvent juge unique puisqu'il juge aussi bien au civil qu'au pénal (Pujol). Les procédures sont simplifiées et adaptées aux situations locales, le mythe de l'assimilation étant rapidement battu en brèche. L'étendue des juridictions est énorme, la population dispersée et les déplacements difficiles. Mais, contrairement à ce qu'affirme Vanderlinden, ces déplacements sont loin d'être insurmontables, les populations n'hésitant pas en Afrique occidentale française par exemple à aller se plaindre directement auprès du gouverneur général à Saint-Louis puis à Dakar si les gens n'arrivent pas à régler leurs affaires localement. Dans tous les cas, les juges sont encouragés à privilégier des processus de conciliation et à rester ancrés dans la vie sociale locale, au risque même de mettre en péril leur indépendance. Parallèlement, la volonté administrative de les mettre sous tutelle persiste, d'où le refus de l'inamovibilité dans les Antilles françaises, le juge ne devant pas échapper aux autorités de la colonie (Durand).

7 Même si ce n'était pas l'objet principal de cet ouvrage riche et détaillé, il est peut-être à regretter que la question de la pratique de la justice par les populations locales et notamment de leurs contacts avec les juges n'ait pas été plus précisément abordée. Une réflexion en termes de genre aurait également pu être introduite car, si les représentants de la justice furent avant le $\mathrm{xx}^{\mathrm{e}}$ siècle sans doute dans leur quasi-totalité des hommes, il n'en demeure pas moins que leurs justiciables étaient des êtres genrés qui ont pu développer des pratiques spécifiques de la justice et avec lesquels le juge a probablement adopté des rapports différenciés. Enfin, il aurait été intéressant de pousser plus loin la réflexion sur la justice coloniale comme «processus de colonisation » qui s'inscrit au cœur d'un rapport de force constant entre colonisateurs et colonisés et qui contribue directement au renforcement de la domination. 